\title{
ATUALIDADE DO PASSADO E LEGITIMAÇÃO DO PRESENTE: UM EXERCÍCIO DE ANTROPOLOGIA HISTÓRICA DA MEMÓRIA (A PROPÓSITO DO EXEMPLO DA REVOLTA OPERÁRIA DE JUNHO DE 1956, EM POZNAN, POLÔNIA)
}

Bogumil Jewsiewicki

À memória de Tony Judt

Os fatos históricos sobre os quais a minha abordagem se apoia são provavelmente pouco conhecidos do leitor brasileiro. Procurarei limitar sua exposição ao mínimo necessário, visando compartilhar sobretudo uma abordagem cujo objetivo principal é o de mostrar que a experiência do presente sempre é informada por uma experiência do passado que a operação de memória torna presente. Para as pessoas comuns, não se trata evidentemente de um passado reconstituído pelos historiadores, mas de um passado que se torna disponível por meio do trabalho da memória histórica. Esta última não constitui um discurso unificado, mas antes uma coleção de modos diversos de coleta do passado, aí incluindo o modo histórico cujo imaginário coletivo assegura a ligação pertinente com o presente. A pertinência, a capacidade de projetar em direção ao futuro o que parece importante no presente, é o princípio de seleção que identifica na memória histórica coletiva o que permite legitimar através do passado este olhar em direção ao futuro. Não há, no entanto, nenhuma dúvida de que a operação vise, antes de tudo, ao presente; ela legitima ou deslegitima um evento, um personagem, uma ação, um julgamento.

Minha ambição é a de mostrar, com base em um exemplo concreto, o do levante operário ocorrido em Poznan, na Polônia, em 1956, ${ }^{1}$ de que modo esta memória trabalha, mas também e sobretudo como ela é manipulada pelos empreendedores da memória. Também pretendo mostrar como a passagem de uma memória viva à patrimonialização faz destes empreendedores, em particular os atores do Estado, poderosos encenadores da memória histórica, cuja forte presença no espaço público marginaliza, 
ou até mesmo condena ao esquecimento a memória viva da experiência. O efeito é ainda mais forte quando estas operações de patrimonialização da memória histórica se inscrevem em um imaginário coletivo (Taylor 2004) amplamente compartilhado.

No caso que me concerne aqui, o imaginário católico confere à nação e a seu Estado qualidades messiânicas (Jewsiewicki 1995b). Minha abordagem analítica, que se vincula tanto à antropologia quanto à história, tem igualmente por ambição mostrar que a oposição entre história e memória somente tem sentido para os empreendedores da memória. O pesquisador deve incessantemente confrontar a operação de memória com o conhecimento histórico, sob pena de ignorar o esquecimento cujo conhecimento é indispensável para a compreensão do modo como opera a memória.

Proponho "descrever o presente por sua história", ${ }^{2}$ expressão que tomo de empréstimo a Oswald Ducrot (2000:158³). Tal ambição seria absurda se não quiséssemos nos limitar a "descrever um presente particular" remetido a um fato singular, situado no tempo e no espaço por uma abundante historiografia e por um intenso trabalho de memória. ${ }^{4}$

O desafio de uma descrição como esta do ocorrido em Poznan em 28 e 29 de junho de 1956 (normalmente limita-se a duração ao 28 de junho $5^{\mathrm{a}}$ feira negra) e dos usos deste fato ao longo dos 50 anos subsequentes ultrapassaria os limites deste texto. Eu me limitarei a propor alguns elementos de uma pragmática ${ }^{5}$ das formas e dos usos da atualização do passado pelo discurso que tornam efetivos aspectos pertinentes do possível. ${ }^{6}$

O levante dos operários da empresa Ciegelski, em Poznan, ocorrido em 28 de junho de 1956, as experiências contemporâneas e ainda os usos memoriais e comemorativos subsequentes e as experiências partilhadas - que estes usos desejavam criar — serão objeto de nossa abordagem. ${ }^{7}$

Fixamos três momentos fortes, junho de 1956, junho de 1981 (o 25을 Aniversário) e, por último, 2006 (o 50 Aniversário). Os dois últimos apresentam-se como comemorações, no entanto, trata-se sobretudo das controvérsias (Latour 2006) sobre o sentido legítimo de Junho de 1956 e de sua posteridade vistos a partir de 1981 e de 2006, portanto, da natureza de sua memória. ${ }^{8}$

A experiência primeira do acontecimento, audível e sensível, bem como suas referências - o passado então evocado para descrever este presente foram rapidamente alocadas na zona do esquecimento coletivo, em grande parte para proteger a sobrevivência do Estado nacional, ponto ao qual voltarei mais adiante. $\mathrm{O}$ esquecimento pelos atores e pelas testemunhas provavelmente fazia parte do pacto tácito entre o poder e os cidadãos que tão somente uma década após o fim da Segunda Guerra Mundial não estavam prontos para enfrentar uma nova guerra. 
Foi preciso esperar a passagem de uma geração e a mudança da situação internacional para que os atores se lembrassem tanto da experiência sensível quanto do passado, descrevendo desse modo por que o levante fora memorável. Eis o relato de um ator:

Ainda hoje, na memória de muitos habitantes de Poznan, as imagens desta marcha são vivas. Eis uma delas. Naquela época, todos os trabalhadores manuais usavam tamancos de madeira. Por esta razão, eles eram ouvidos de longe, por conta do surdo ruído dos tamancos sobre o solo. A cena evocava um campo de trabalho. O barulho ritmado dos tamancos, os rostos determinados, os punhos serrados e as vestimentas miseráveis de operários completavam a imagem que evocava os anos trágicos da ocupação da Polônia [o autor evoca a ocupação pela Alemanha nazista por ocasião da Segunda Guerra Mundial].

Nas primeiras fileiras, avançavam as mulheres. Na fábrica, elas executavam tarefas muitos pesadas, quase inumanas. Elas caminhavam em seus tamancos que não haviam afivelado, as fivelas pendiam e voavam a cada passo. Eis a verdadeira carta de visita da produção para exportação que se supunha tornar célebre em toda Europa a reputação do operário polonês [...].

Os transeuntes, sobretudo as mulheres, choravam ao cruzá-las. A verdade mais crua tinha saído às ruas para mostrar à cidade sua verdadeira face. ${ }^{9}$

A configuração dos discursos (livros, imagens, monumentos, performances comemorativas, museificações etc.) compõe um lugar de memória no sentido preciso que Pierre Nora (1997:2226) conferiu a este termo. ${ }^{10}$ O "Junho 56"11 é tanto um lugar de memória quanto um fato histórico. Devido à sincronização dos discursos (dos quais muitos se apresentam a nós em ordem diacrônica de produção), um lugar de memória constitui o contexto de sua atualização histórica, ele é um "conjunto de entidades que somente são constituídas por suas relações mútuas" (Ducrot 2000:148). ${ }^{12}$

Entre 1956 e 1980, o Estado impõe um silêncio ou até mesmo um esquecimento de Junho de 1956, incluindo Poznan. O esquecimento e o silêncio são componentes essenciais. O poder - apoiando-se sobre o controle quase total do espaço público e sobre um acordo tácito com a sociedade (datado de outubro de 1956) para evitar qualquer provocação em relação à URSS, visando proteger a soberania nacional — tem êxito em tornar Junho de 1956 ausente da memória nacional, mesmo em Poznan nos anos 70.

Ele ocupa, no entanto, um lugar importante na memória da nação resistente, na qual os fatos históricos adquirem um valor simbólico fora do tempo e do espaço. Apesar da interdição da presença no espaço público imposta com a proclamação do estado de guerra, em dezembro de 1981, Junho de 
1956 não cessou — até 1989 - de estar onipresente como arma contestatória da legitimidade do Estado e de sua submissão à URSS. O contraste do trabalho de esquecimento entre dois períodos, 1956 a 1980 (nascimento do Solidarnosc em Gdansk) e 1981 (construção do monumento em Poznan em relação dialógica com o monumento de Gdansk), em 1989, ilustra de modo exemplar que o esquecimento não é efeito nem de uma relação bruta de forças nem da distância cronológica. Por falta de espaço para analisar explicitamente, reitero simplesmente minha firme convicção em considerar o esquecimento como um componente ativo de constituição e transformação de um lugar de memória.

Evidentemente, não abordarei o fato total Junho de 1956 - esta totalidade me escapa - limitar-me-ei a considerar os discursos. ${ }^{13}$ Cada um deles, em seu contexto particular, apreende o fato, congela-o a fim de evidenciar o que é pertinente do ponto de vista do contexto social, daquele do ator social, autor ou leitor para evidenciar o que dele retém o "discurso questionador", segundo a expressão de Foucault.

Não há espaço aqui para nos engajarmos em uma discussão sobre a relação entre o conceito foucaultiano de "episteme", ${ }^{14}$ o conceito de imaginário e a noção de quadro social da memória (Halbwachs 1994). Neste texto, a preferência por este último se deve ao interesse pela memória. A abordagem de Maurice Halbwachs permite historicizar o trabalho de memória (Lavabre 2006) e adotar a seu respeito a postura weberiana de neutralidade axiológica. O pesquisador que se debruça sobre a "ciência dos atores" - e o trabalho de memória é um deles - renuncia a ter logo de saída julgamentos sobre os atores. Assim, os contextos sociais da memória lhe são indispensáveis para "analisar as operações críticas realizadas pelos atores sociais no decorrer da vida cotidiana" (Boltanski 2000:306). Contemporâneos, estes atores "compartilham a mesma atualidade histórica" (Descombes 2000:22), ${ }^{15}$ inscrevem-se em uma ordem de mudanças, uma temporalidade. "A atualidade histórica, escreve Descombes (:29), consiste no concurso histórico dos processos em curso, fonte de interferências mútuas". Uma vez que o contemporâneo é uma relação entre todos os elementos da atualidade, a tarefa dos pesquisadores é a de explicitar "em quais condições se faz, para nós, no mundo que é o nosso, o concurso temporal das diferentes mudanças em curso e das diferentes ações engajadas que compõem a nossa atualidade" (:31).

Analisar a contemporaneidade dos discursos que produzem um evento significa renunciar à análise do passado do ponto de vista da posteridade (abdicar da postura da história que julga, abandonar a tradição hegeliana, declarando o real racional uma vez que advindo ${ }^{16}$ ) para adotar o ponto de vista da contemporaneidade. Entre posteridade e contemporaneidade, a 
diferença é antes afetiva que cognitiva, insiste Descombes. Cólera, deleite e dor são afetos orientados para o que é atual, o passado pode ser sobretudo digno de arrependimento ou memorável, o futuro desejável ou temido. O contemporâneo nos toca, portanto, por seu caráter irritante, doloroso ou delicioso e, no entanto, "[...] as paixões do contemporâneo não devem ser computadas nas misérias da condição humana. São as paixões de um ator mergulhado nos acontecimentos para ele atuais" (:31). Ao menos em sua recepção memorial, os afetos tornam um passado atual. O presentismo que, após a derrubada do muro de Berlim, constitui, segundo François Hartog (2003) nosso regime de historicidade, trocou a racionalidade formal da linearidade cronológica do progresso pela relação afetiva com o passado. A partir de então, será por sua contemporaneidade que um passado se distinguirá de um outro que nossos discursos teriam podido apreender. ${ }^{17}$

A atualidade sendo o tempo mesmo da ação, aquele em que o possível torna-se efetivo [...], o atual não é o presente - mesmo que nos seja mais difícil restituir a uma ação passada a dimensão de sua atualidade (Bazin 2000:43).

É no presente que os atores produzem o contemporâneo, mas o que é passado propõe ingredientes necessários para tanto. É no tempo, uma ordem no interior da qual tomamos consciência e ato das mudanças, que ocorrem as retomadas do passado, estas realizações das potencialidades que ainda não foram e talvez jamais sejam realizadas (Lepetit 2000:63). Congelados pelos discursos, ferramentas de construção dos eventos contemporâneos, os fatos advindos estão presentes - pela metade - novamente representados (Ricoeur 2000). Tais representações resultam tanto de um trabalho de rememoração quanto de esquecimento, já que o significado de um discurso somente pode ser plenamente apreendido no trabalho da memória e do esquecimento. ${ }^{18}$ A presença do ausente é uma ação e "o esquecimento é uma condição necessária para a ação". ${ }^{19}$

A análise das presenças (representações, no sentido forte desta noção) de Junho de 1956 procura evidenciar os agenciamentos atuais de uma configuração histórica (Castel 2000:176), reorganizando, em primeiro lugar, diacrônica e sincronicamente as experiências e as memórias vivas de Junho de 1956 em vias de produção. Em seguida, a comemoração que, entre 1981 e 1989, produziu seu espaço, seu "próprio", ${ }^{20}$ e por fim a comemoração de 2006. Cada um destes eventos ${ }^{21}$ existe para os atores sociais, inscreve-se em uma atualidade histórica e nos é inteligível porque os discursos que os dão a conhecer são produzidos e recebidos na sincronia. Para fins analíticos, é possível dissecar uns e outros, como se disseca em laboratório um organismo 
vivo, ${ }^{22}$ com o mesmo efeito da impossibilidade de tornar a dar vida ao organismo dissecado.

Somente levarei em consideração três macroeventos situados em suas atualidades históricas respectivas, levando em conta a dupla contemporaneidade de cada um deles. Contemporaneidade que marca uma época, ${ }^{*}$ certamente, mas sobretudo contemporaneidade modal, uma vez que permite apreender a passagem do potencial ao possível, de compreender o que, em 1981 e em 2006, comemorar queria ou teria podido querer dizer. ${ }^{23}$ Uma vez que não disponho de meios de pesquisa que me permitam considerar a recepção (Jauss 1982), eu me limitarei a indicar as ambições, os objetivos esperados dos autores dos discursos que produziam cada comemoração e, em certo sentido, a presença, congelada pelo discurso e distinta a cada vez, do fato histórico. Notemos, antes de mais nada, que mesmo que se presuma que Junho de 1956 esteja na origem de cada comemoração, ele deixa rapidamente de ser seu objeto imediato, aquele que a comemoração torna presente. No que tange à experiência dos atores em 2006, foi antes o monumento erigido em 1981 do que Junho de 1956 o que foi representado.

Ler comparativamente os discursos que tornam atual a memória de Junho de 1956 remete necessariamente à tradição foucaultiana da "arqueologia do saber" (1969) e à abordagem de Lieux de mémoire de Pierre Nora (1997). Na perspectiva dos trabalhos de Foucault, em particular tal como interpretados por Paul Veyne (2008), Junho de 1956 enquanto objeto de conhecimento somente nos é acessível pelo discurso, o qual, contudo, enquanto modalidade da atualidade histórica não é um obstáculo ao conhecimento. ${ }^{24}$ Ao contrário, é sua condição, uma vez que é o discurso que nos força a viver em nosso tempo. Os discursos nos tornam contemporâneos e copresentes uns em relação aos outros, porque uma ligação hermenêutica entre os humanos permite compreender o discurso que não necessariamente compartilhamos. ${ }^{25}$

No plano diacrônico, a relação com o passado que atualmente chamamos de "memória" é uma modalidade discursiva de nossa contemporaneidade, específica do regime de historicidade qualificado por François Hartog como presentismo. ${ }^{26}$ No plano sincrônico, temos o hábito de qualificar de cosmopolita a modalidade de copresença dos discursos.

Ao invés da sucessão formal na cronologia, são o espaço social de referência e as relações com o poder que os distinguem uns dos outros. ${ }^{27}$ Estas

* [N.T.] No original, o autor utiliza o termo épochal, um neologismo que denota um novo tempo, algo que funda uma nova época, um evento que, no futuro, será lembrado como fundador, ainda que no momento de sua ocorrência não tenha sua importância devidamente percebida. 
duas modalidades discursivas de abolição do "dessemelhante", modalidades de partilha de uma duração e de um espaço, contribuem para a produção de uma contemporaneidade. Quando Pierre Nora intitula o terceiro tomo de Lieux de mémoire de "Les France", o artigo no plural visa menos aos estados sucessivos "da França" que às suas realidades discursivas no presente, maneiras de habitar "a França" hoje e de apreender faces do passado como memórias.

A abordagem proposta por Foucault apreende o conhecimento ${ }^{28} \mathrm{de}$ um fato (seu objeto) na descontinuidade de escolhas dos ângulos de leitura que revelam este quê, de um discurso a outro, apreendido como pertinente. O discurso congela em um fato do passado um evento do presente, ele torna um passado contemporâneo. O "discurso questionador", o objeto - no qual este discurso congela o evento - e o sujeito conhecedor emergem conjuntamente.

A abordagem do "lugar de memória" repousa sobre a leitura simultânea dos discursos ${ }_{1}^{29}$ os quais enquanto modalidade de atualização dos fatos do passado produzem o evento memorial em sua pluralidade. Sem recolocar em questão a singularidade da história do pensamento, no coração da obra de Foucault, a abordagem do "lugar de memória" torna possível o vagar ${ }^{30}$ entre o discurso contemporâneo e os discursos que atualmente parecem marginais, menos verdadeiros ${ }^{31}$ (antigos, arcaicos, exóticos), já que se beneficiam significativamente dos efeitos específicos do poder.

Considerar Junho de 1956 como lugar de memória permite examinar historicamente meio século de memórias transformadas em eventos. Cada discurso (livro, imagem, objeto, monumento, performance, locução etc.) procede de uma escolha única daquilo que no fato histórico ocorrido foi retido como pertinente.

As rememorações sucessivas "lembram-se" 32 daquelas de outrora, referem-se explicitamente a algumas delas e sobretudo as esquecem, tanto por omissão quanto propositadamente. No caso de Junho de 1956, percebemos que a sucessão dos discursos memoriais e dos eventos que tais discursos tornam contemporâneos oscila entre dois ${ }^{33}$ lugares de memória. De um lado, Junho de 1956 é um lugar de memória polonês, memória nacional abrigada sob o estandarte do patriotismo; ${ }^{34}$ por outro lado, é um lugar de memória europeu sobre o qual paira a sombra internacional (no sentido da longa tradição de solidariedade para com aqueles que se batem contra os tiranos, não no sentido das relações internacionais) que não ousa se revelar, já que na Polônia atual a Internacional representa algo ainda pior que o comunismo, ela significa a ocupação soviética. ${ }^{35}$ Às vezes, os dois lugares de memória sobrepõem-se, às vezes se distinguem pela vontade explícita dos atores de 
comemoração. Por ocasião do $25^{\circ}$ Aniversário, o tom claramente nacional da representação de Junho de 1956 no espaço público dissimula, sem no entanto esconder o antissovietismo. ${ }^{36}$

O trabalho de comemoração estende um espelho à nação, as cruzes do monumento cuja presença preenche o espaço público do catolicismo histórico polonês. Esta presença transbordante expulsa a ideologia comunista, percebida - sobretudo retroativamente - como a expressão do "colonialismo" soviético. Tal como as roupas novas do rei, o embate real não é visível, uma vez que a relação política ${ }^{37}$ proíbe nomeá-lo. Mais tarde, o $50^{\circ}$ aniversário inscreveu-se explicitamente no horizonte de expectativas ${ }^{38}$ advindo da queda do comunismo. A nação católica polonesa passava então do estatuto histórico de mártir àquele de portador do bastião do anticomunismo (antissovietismo), do qual o Solidarnosc constituiu o braço armado. Em 2006, Junho de 1956 esteve presente como ato fundador da irresistível ascensão das nações contra o comunismo, contra o império soviético, mas também como ponto nodal de articulação entre a longa luta contra as potências que partilharam a Polônia até 1918 e aquela contra a dominação soviética. A tribuna política que o presidente da Polônia compartilhava, na ocasião, com os presidentes de países vizinhos não faz sombra às cruzes do monumento de 1981 que domina a comemoração. O fato histórico Junho de 1956 é representado nesta comemoração pela vítima inocente Romek Strzalkowski, criança de 13 anos, o mártir. ${ }^{39}$ Um espetáculo público apresentado em Poznan, em seguida posto em circulação em um CD, fez dele tanto um Gavroche quanto uma Marianne. ${ }^{*}$

Ao inserir a memória de Junho de 1956 no imaginário cultural europeu da Revolução Francesa, seu idealizador (Izabella Cywinska, coautora da peça de teatro de 1981) confere à tomada do edifício SB (serviço de segurança do Estado), em Poznan, ares de uma tomada da Bastilha do comunismo soviético. ${ }^{40}$

Cada uma das contemporaneidades produzidas respectivamente em 1956, 1981 e em 2006 imprimiu no campo discursivo sua configuração hegemônica; cada uma fabricou seu evento Junho de 1956. A partir de um fato advindo, três objetos de conhecimento distintos foram congelados pelo discurso: o efeito de verdade ${ }^{41}$ de cada um destes discursos mede-se em

* [N.T.] Marianne é a figura alegórica da República francesa, encarnando os valores representados na insígnia "Liberdade, igualdade, fraternidade". Gavroche é um personagem do romance Os miseráveis, de Victor Hugo, arquétipo de uma criança parisiense do século XIX, debochado e engenhoso. 
relação a seu objeto de conhecimento e não em relação ao fato histórico global. ${ }^{42}$ Para o historiador da memória, existe um fato do passado que, de início, não tem nome e cuja extensão ao longo do tempo e no espaço depende do ponto de vista do observador. Sua atenção volta-se, entretanto, para os três eventos de Junho de 1956 e para os processos de suas construções. ${ }^{43}$ A apreensão do fato tem uma geometria variável, pode limitar-se sua duração ao próprio levante, ao levante seguido de perseguições e do processo. Pode-se ampliá-la aos usos de Junho de 1956 por Solidarnosc (notemos um silêncio de 20 anos entre os dois). Quanto ao espaço, podemos identificá-lo com o empreendimento Cegielski, organizá-lo antes em torno da área da segurança de Estado tomada pelos manifestantes, ampliá-lo à nação, à região da Europa central, ou mesmo da Europa "livre".

Não se deve concluir que os acontecimentos fabricados desse modo se oponham necessariamente, que os atores ou leitores de um ignorem os outros. Cada discurso e acontecimento, se o discurso chega a gerar um, são produzidos e recebidos sincronicamente, em uma configuração organizada pelo "discurso questionador".

O discurso questionador pode ignorar os acontecimentos outros que não o seu. Os atores sociais contemporâneos - que ele procura situar em posição de contemporaneidade em relação a este acontecimento - não são evidentemente desprovidos nem da memória histórica nem da faculdade crítica. Eles podem desnudar um discurso, tornar aparente seu caráter arbitrário. Contudo, a exemplo dos bem-aventurados do Evangelho de João, é digno de mérito acreditar sem ter visto, ver, crer, ignorando o que por outro lado se sabe, se viu ou se escutou.

Em junho de 1956, ser contemporâneo de Junho de 1956, quando aquilo que se produzia ainda não tinha nome, ser parte interessada fora de Poznan ou da Polônia situava a experiência e a ação de cada um sob a iluminação da confrontação entre um campo de experiência e um horizonte de expectativas. A memória viva corria no fluxo das experiências vividas, a memória histórica fornecendo um contexto social, um tempo e um espaço a fim de fabricar um evento. No entanto, para a maioria, tal como Fabrice em a Chartreuse de Parme de Stendhal, os atores somente eram testemunhas daquilo que advinha de suas ações na temporalidade e no espaço. Contudo, para além do primeiro instante, e provavelmente até mesmo nele próprio, um primeiro discurso encarregava-se da experiência para que a memória surgisse e conferisse um sentido à experiência, a fim de que o evento decantasse em seguida a inserção da sincronia na diacronia do efêmero.

Vários testemunhos (fotografias, declaração registrada ao vivo, texto escrito etc.) sugerem que o barulho dos tamancos sobre o pavimento ${ }^{44}$ possa 
ter agido como primeiro discurso escutado simultaneamente pelos operários que avançavam e por aqueles que os viam. No plano da ação em vias de produção, este barulho - ambiente em situação de trabalho, estranho na rua - articulava ali, onde milhares de passos ressoavam, o nome da revolta, dava a ouvir a determinação e a força da ação comum. Ele notificava a razão direta da ação (condições de trabalho inaceitáveis ${ }^{45}$ ), a força apoiada na tradição de suas lutas operárias e no sentido de pertencimento à empresa. Por parte dos espectadores, a princípio por acidente, este barulho havia produzido os primeiros testemunhos ${ }_{1}^{46}$ subitamente conscientes de assistir a uma ação portadora de sentido, conscientes também da obrigação de conservar o testemunho. Nas horas e nos dias que se seguiram, outros atores, outras ações se revezaram, suas contemporaneidades foram articuladas por outros discursos sincronicamente tornados presentes a fim de conservar e representar o que havia ocorrido e o que ocorreria.

Provavelmente fortuita, a presença da imprensa internacional - excepcionalmente numerosa nessa época em um país do bloco soviético - teve um importante papel. As rádios ocidentais, na ocasião captadas na Polônia, mencionavam o ocorrido, contribuindo para a percepção da revolta como acontecimento que marca uma época, privilegiando aqueles que, tal como Chateaubriand, atribuem a um fato recém-ocorrido um julgamento do ponto de vista da posteridade. ${ }^{47}$

Na primeira página de um jornal londrino, uma foto tirada por um repórter que viera cobrir a Feira Internacional de Poznan produziu, desse modo, um evento diferente, evento que marca uma época, que reenvia o barulho dos tamancos às reservas da memória, ao museu provincial. Esta foto articula então um discurso radicalmente diferente sobre Junho de 1956, mobiliza um tempo e um espaço que tornaram o barulho dos tamancos provincial, banal. $\mathrm{Na}$ foto, na primeira fileira de manifestantes, vemos caminhar uma mulher que a vestimenta não identifica como operária. ${ }^{48}$ Acima dela flutua a bandeira polonesa manchada, que parece cair sobre ela, protegê-la. O contexto de leitura (mais tarde a ele serão acrescentados os testemunhos afirmando que ela a teria recolhido na rua) sugere que a bandeira manchada de sangue teria sido recolhida das mãos de um manifestante tombado a tiros. Segundo o contexto da memória retida, esta figura feminina pode ser uma encarnação da Marianne sobre a barricada, da Virgem protetora da Polônia, da mãe polonesa realizando a tarefa inacabada pelo marido ou pelo filho tombado a tiros. Cada discurso articulou, assim, sua memória à experiência, mas também aí interveio, uma vez que a recepção é sincrônica à perseguição da experiência.

Os discursos procuram conferir um sentido ao que advém, inscrevendo a ação em uma memória histórica, projetando-a no futuro do horizonte de 
expectativas. A recepção destes discursos faz emergir outros atores, reenvia à sombra os atores de primeira hora, coloca a utopia no lugar da memória para representar como já advindo o que ainda virá. ${ }^{49}$ Herdeiros de Chateaubriand tomam pé nesta posteridade, situando-se como testemunhas do evento que marca uma época, do futuro que dão à luz. O quadro social que mobilizam favorece a articulação com as expectativas e as sensibilidades da recepção de um discurso cuja hegemonia se impõe.

A memória cultural (Assmann 2006) leva a reconhecer aí as correspondências entre um regime de verdade e o objeto de conhecimento em vias de construção. Assim, se torna hegemônica a autorreferencialidade memorial (memória do futuro inelutável, de um futuro advindo) de Junho de 1956. Extraído do tempo como ordem de mudanças, o discurso sobre Junho de 1956 inscreve-se no processo de reconhecimento dos sinais da presença do futuro. O monumento comemorativo pode então se tornar o objeto central da comemoração - a representação ou o sentido de presença do ausente de Junho de 1956.

Após a queda do muro de Berlim, retomar seu lugar no patrimônio europeu não quer mais dizer para a nova Polônia acrescentar quadros "em uma velha casa na qual se veem antigos quadros nas paredes"..$^{50}$ Deseja-se contribuir para a mudança da coleção a fim de reafirmar esta casa cristã. Pela primeira vez na história das comemorações de Junho de 1956, em 2006, o Estado polonês se apresenta por inteiro, com sua legitimidade nacional reencontrada. Seu presidente arvora-se como principal oficiante do evento europeu e cristão de Junho de 1956. Em 2006, contrariamente a 1981, apesar da farta documentação, ${ }^{51}$ apesar da disponibilidade de alguns atores ainda vivos, a comemoração de Junho de 1956 não se liga nem com o tempo do fato histórico nem com as experiências dos atores pronunciadas por eles próprios.

Esta comemoração inscreve o Junho de 1956 - representado pelo monumento de 1981, atualizado pelo acréscimo da data de 1981 - no tempo conjuntural da construção da legitimidade de um presidente que se apresenta como polonês católico, logo anticomunista. O destino heróico nacional sendo realizado, a história inevitavelmente se aproxima de seu final. A memória da contribuição dos poloneses ao nascimento do mundo democrático às Revoluções americana e francesa, em seguida à Primavera dos Povos valoriza a representação de Junho de 1956 como signo anunciador do fim da história. ${ }^{52}$ Contra as hordas de usurpadores e traidores, "autêntico" depositário do espírito e da palavra do sindicato Solidarnosc, o presidente coloca-se como guardião do legado. Em 2006, Junho de 1956 somente tem significado por meio do Solidarnosc que ele teria originado e somente saberia ser comemorado de outro modo nesta posteridade advinda. 
Tal posteridade está inscrita no monumento em datas que identificam as etapas de realização do sentido da história, a lista tendo sido coroada pela inclusão de 1981, data da primeira comemoração pela construção do monumento. As datas figuram no centro do monumento em cruz, a cruz com inscrição 1956 à esquerda e a águia polonesa à direita. A posteridade - mas será a de Junho de 1956 ou a de sua comemoração em 1981? — oferece um ponto de vista para receber o espírito cristão da nação, verdadeiro herói da luta contra o mal comunista. ${ }^{53}$ Desde a Primavera dos Povos de 1848 a $1989,{ }^{54}$ o outono triunfal de seu retorno ao "mundo livre", a Polônia cristã sacrificava seus melhores filhos para promover a liberdade dos outros. Filhos da nação cristã, eles julgavam o presente do ponto de vista da posteridade que deveria advir; armados assim da memória do futuro, eles não podiam enganar-se de causa.

Em 2006, filha da Igreja, a Polônia cristã chorava ao pé do monumento de Junho de 1956, e não mais aos operários defendendo seus direitos, mas sim ao inocente, o mártir tombado sob as balas comunistas. Este mártir taumaturgo, Solidarnosc, tendo nascido de seu sacrifício, ${ }^{55}$ purifica a nação e exorcisa-a do mal do passado. ${ }^{56}$ De operária e antitotalitária nas primeiras horas da revolta de 1956, em seguida, de heróica e combatente nos anos 1980, ocasião em que foi trazida por Solidarnosc liberada do "dever de memória", 57 a memória de Junho de 1956 torna-se então o evento sacrificial. ${ }^{58} \mathrm{O}$ presidente Kaczynski pode se servir para colocar à sua maneira o problema do $\mathrm{Mal}^{59}$ que desde a Segunda Guerra Mundial assombra a consciência europeia. ${ }^{60}$

Na atualização do massacre dos inocentes e da crucificação, a comemoração de 2006 identifica o Mal ao comunismo, sobre cuja origem estrangeira, ou até mesmo diabólica, não paira qualquer dúvida. Nação cristã, para que a Polônia mereça seu lugar na vanguarda da última cruzada, ainda lhe será preciso sofrer a purificação pela descomunização, ação da qual o presidente será cavaleiro. Sua morte acidental em 2010 permitirá a seu fiéis transformá-lo em mártir nas mãos dos russos, um mal encarnado, já que não são somente ortodoxos e inimigos históricos da nação, mas ainda por cima comunistas mal arrependidos.

Quem decide o evento?

Porque o evento decisivo é um instante do tempo no qual se decide o sentido do que se produz ou se produzirá em qualquer tempo, ninguém é verdadeiramente seu contemporâneo. Eis porque há uma equivalência hermenêutica entre a primeira testemunha, aquela que assiste ao acontecimento histórico, e o simples leitor dos relatos deixados pelas testemunhas humanas. Já a primeira testemunha, caso tenha atribuído qualquer significado aos eventos nos quais se viu envolvida, já teve de interpretá-los. 
Os contemporâneos assistiram aos acontecimentos de nosso passado, mas não têm privilégio sobre nós no que diz respeito ao sentido destes acontecimentos (Descombes 2000:29). ${ }^{61}$

Quando o discurso dota o evento do sentido prometeico, os contemporâneos do fato apagam-se no esquecimento para ceder lugar às testemunhas acampadas na posteridade que reivindicam a autoridade do tribunal da história. A memória confunde-se então com a escrita histórica, com o discurso do "historiador que parece encarregado da vingança dos povos". ${ }^{62}$ Do ponto de vista da necessidade histórica, ela julga o que se passou a título do que deve se passar.

[...] aquele que aprendeu antes de tudo a se curvar e a baixar a cabeça diante da "potência da história" terminará também por aderir a qualquer potência quer seja a de um governo, de uma opinião pública ou de uma maior quantidade [...] (Nietzsche 1990:147).

Recebido em 09 de setembro de 2010

Aprovado em 23 de setembro de 2010

Tradução de Roberta Ceva

Bogumil Jewsiewicki, atualmente aposentado, é membro do CELAT e foi titular da Cadeira de Pesquisa em História Comparada da Memória, na Universidade Laval, Canadá. E-mail: <Bogumil.Koss@hst.ulaval.ca>

\section{Notas}

${ }^{1}$ A pesquisa documental é fruto de um trabalho coletivo com meus colegas da Universidade de Poznan, Maria Kujawska e Izabella Skorzynska, a quem agradeço aqui. Agradeço igualmente a Ewa Domanska, da mesma universidade, por ter mencionado o volume de Henryk Ladorski.

${ }^{2}$ Há um século e meio, em 1858, Ernest Renan, citado por Paul Veyne (2008:60, nota 3), escreveu: "A história, ou melhor, a história do espírito humano, é neste sentido a verdadeira filosofia de nosso tempo". Mais tarde, Nietzsche advertia que 
a inteligência não tem missão que ultrapasse a vida humana. Mais tarde ainda, Foucault (1969:66) insistia que os objetos, o campo semântico com seus conceitos e o discurso formam um todo no qual o discurso explica que tal coisa seja vista ou omitida, vislumbrada sob tal aspecto, analisada em tal nível, mas que o homem não pode aceder a toda a verdade, uma vez que ela não existe em lugar nenhum. Não há adequação completa entre o discurso e seu objeto, a parte da coisa considerada pertinente muda de um momento discursivo a outro. Somente podemos conhecer fatos singulares, nada mais do que realidades históricas advindas de um determinado tempo e lugar.

${ }^{3}$ No mesmo volume, originado de um colóquio da EHESS de 1995, Jacques Revel (2000:14-15) inscreve-se na tradição dos trabalhos de Nathan Wachtel e dos Lieux de mémoire de Pierre Nora para afirmar a historicidade "essencial do presente e daqueles que pretendem partir do presente e falar a partir do presente".

${ }^{4}$ A noção é de Paul Ricoeur (2000).

${ }^{5}$ Em seguida a Luc Boltanski \& Laurent Thévenot (1991).

${ }^{6}$ A leitura memorial opõe-se à recepção dos textos de historiadores cujo efeito é descrito do seguinte modo por Jean-François Lyotard (1991:61): "O que parece necessariamente perdido é a presença do que é agora passado. O que é agora necessário, imutável, era então contigente. O que já não tem poder (já não tem possível) agora era então poder ou força".

${ }^{7}$ O leitor que não lê polonês pode se reportar a Lawrence Goodwyn (1991). O segundo capítulo traz uma excelente análise descritiva das jornadas de 28 e 29 de junho de 1956.

${ }^{8}$ A placa que reúne as comunicações apresentadas por ocasião do colóquio dedicado ao $50^{\circ}$ aniversário na Universidade de Poznan intitula-se Junho de 56 de Poznan. O sentido da memória. A conferência de abertura insistia sobre a "pesquisa de um modelo de memória, da maneira de guardar na memória" (Sojka 2006:8).

${ }^{9}$ Henryk Ladorski (Niepokonani '56 Poznań. Poznań: Pallotinum, 1992) nos traz o testemunho de J. Wielgosz. Em 2009, ocasião em que ministrei em Poznan uma conferência baseada neste texto, Mieczyslaw Kujawski lembrou-se de sua experiência de transeunte. Estudante, na época, ele dirigia-se de manhã cedo a um exame quando lhe chamou a atenção o ruído inabitual de tamancos sobre o pavimento; inabitual porque ritmado, assinalando a marcha de muitos, ao invés do barulho habitual de passos de operários caminhando separadamente para ir ao trabalho. Por muito tempo, ele foi marcado por esta passagem da experiência sonora dos barulhos ambientes do cotidiano na experiência do memorável - já que o presente foi então descrito pelo passado da ocupação alemã. Em ambos os casos, o passado convocado para descrever o presente assimilava o Partido Comunista polonês e seus patrões soviéticos à ocupação nazista, bem como a miséria operária desnudada contradizia no espaço público o discurso do Partido, que se colocava como vanguarda do proletariado. 
${ }^{10}$ Nora define o lugar de memória como "toda unidade significativa, de ordem material ou ideal, cuja vontade dos homens ou o trabalho do tempo transformou em um elemento simbólico do patrimônio da memória de qualquer comunidade", e relembra no início do primeiro tomo (1997:17) que "Os lugares de memória não são aqueles dos quais nos lembramos, mas ali onde a memória trabalha".

${ }^{11}$ O vocábulo se impôs a partir da primeira comemoração pública em 1981. O Comitê Social para a construção do monumento de Junho de 1956 de Poznan já o incluía em sua apelação, mas o ano figura então por completo. O volume, à cuja redação o Comitê dá início, impondo às autoridades a publicação, tem como título Poznanski czerwiec 1956 (Jaroslaw Maciejewski \& Zofia Trojanowiczowa), Poznan, Wydawnictwo Poznanskie, 1981, segunda edição em 1990. Este volume contém principalmente testemunhos de história oral, poderíamos dizer, colhidos pela primeira vez desde 1956.

${ }^{12}$ Ducrot escreve mais adiante (2000:149): "Apresentar um conjunto de fatos como sincrônico [...] não é enunciar um fato, mas tomar uma decisão. Escolhemos, por razões que não são de ordem cronológica, sublinhar aqui mais do que lá as fronteiras da simultaneidade".

${ }^{13}$ Pierre Bourdieu escreveu (1980:57): "O discurso que diz a ação [...] não deve cessar de dizer que ele não faz senão dizer a ação. Nós fazemos o possível para respeitar esta injunção".

${ }^{14}$ Paul Veyne (2008) propõe uma leitura que libera a obra do filósofo historiador dos incontáveis comentários que a tornaram frequentemente indigesta. Tanto quanto possível, seguiremos a leitura proposta por Veyne.

${ }^{15} \mathrm{O}$ conceito de atualidade de Vincent Descombes é modal, o atual define-se por contraste com o potencial ou o possível.

${ }^{16}$ Nietzsche (1990:147) escrevia em um texto célebre do qual somente nos lembramos de uma frase: "Se todo sucesso contém em si uma necessidade racional, se todo evento é a vitória da lógica ou da 'ideia' - então, rápido, de joelhos, e que nos ajoelhemos sobre todas as marchas dos 'sucessos'". Também poderíamos lembrar de inúmeras passagens de Paul Valéry.

${ }^{17}$ Os historiadores estão derrotados, muitos estão revoltados, os comitês e os apelos por vigilância multiplicam-se na França e alhures. Ver, entre outros, Christophe Prochasson (2008).

${ }^{18}$ Ducrot (2000:149) escreve: "Mesmo se temos tendência a esquecer estes discursos, trata-se, para mim, de uma espécie de esquecimento freudiano que recobre uma memória".

${ }^{19}$ Escreve Emmanuel Terray (2000:183) que persegue "O sentimento de necessidade ilusória engendrado pela leitura de uma parte não negligenciável da história 
escrita acarreta, de fato, para esta última, um inconveniente importante: ela se torna inútil para a ação [...] não a reprodução do que é, mas a experimentação, a invenção, a transformação do real".

${ }^{20}$ A representação necessita de um lugar, de um "próprio", a partir do qual as estratégias memoriais podem ser lançadas. Solidarnosc, que se apresenta como herdeira, em junho de 1956, ganha então um segundo "próprio" (o canteiro naval de Gdansk e o monumento da revolta de 1970 são os primeiros), no sentido dado a este termo por Michel de Certeau (1980). Sua capacidade de agir de forma estratégica foi consideravelmente aumentada, como se pôde constatar por ocasião do estado de guerra.

${ }^{21}$ A distinção entre fato e evento é arbitrária. Neste texto, nós chamamos "fato" o que adveio de sua materialidade, sua atualização histórica sendo chamada "evento".

${ }^{22}$ Desde Foucualt, uma abundante literatura de antropologia do conhecimento experimental nos fez compreender que também no laboratório somente se vê e se descreve o que é, em um dado momento, social, cultural e epistemologicamente visível.

${ }^{23}$ Parafraseando o célebre título do não menos célebre livro de Pierre Bourdieu (1982).

${ }^{24}$ Quando a ele aplicamos a crítica genealógica, a partir do momento em que se explicita o arbitrário, os limites do discurso aparecem. No entanto, nada permite extrair daí o objeto em estado puro, já que o objeto de conhecimento em estado puro não existe.

${ }^{25}$ Também podemos dizer, seguindo Jacek Sojka (2006:8), que se inspira em Paul Ricoeur: "O passado não é o que já não é, mas o que foi. O que foi esperado, em certo sentido, ser dito". Sojka é o organizador da já citada conferência comemorativa da Universidade de Poznan.

${ }^{26}$ Vincent Descombes (2000:27) propõe abandonar a oposição antigo/ moderno para dar lugar, ao lado do antigo (païen) e do moderno, às coisas que ocorreram antes do antigo (o arcaico) e àquelas que ocorreram alhures, em outro lugar que não na história marcada pela revolução do antigo em novo (o exótico).

27 “Tudo o que pensam e fazem os homens, suas sociedades, é arbitrário e muda de uma época para outra, já que nada de transcendente, nem mesmo de transcendental guia o devir imprevisível da humanidade", escreve Paul Veyne (2008:11).

${ }^{28} \mathrm{O}$ conhecimento é uma interação entre duas realidades espaço-temporais, o indivíduo e seu meio, ela é um processo empírico e não um espelho do real. Lembremos também de Jean-Marie Schaeffer (2007).

${ }^{29}$ É por esta razão, entre outras, que o mergulho em historiografia é tão importante para Nora. Ele elabora uma história da historiografia, contudo, contrariamente 
à modalidade histórica, não procura polir a racionalidade do real pela relativização das diferenças explicadas pelo contexto de fabricação da história como conhecimento, mas em valorizar as diferenças, ou mesmo o "dessemelhante" a título de modos de presença desta fabricação.

${ }^{30} \mathrm{O}$ homem "é um animal errático sobre o qual não há nada a saber para além de sua história", escreve Paul Veyne (2008:113).

${ }^{31}$ Foucault (1994b:159) escreve que a verdade é "o conjunto de regras segundo as quais separamos o verdadeiro do falso e vinculamos ao verdadeiro os efeitos específicos de poder". No pensamento foucaultiano: "a verdade tem uma essência que é a de corresponder a seu objeto", explica Veyne (2008:109), mas ela não tem origem porque apenas existe no discurso que a enuncia, discurso que somente tem existência histórica, portanto, específica a um dado momento e lugar. Um acontecimento "modifica a essência da verdade" (escreveu Heidegger) não somente porque o discurso mudou, mas também porque "a parcela da coisa considerada como pertinente" mudou (Foucault 1994c:632). Desse modo, é possível dizer em certa época alguma coisa que jamais foi dita anteriormente (Foucault 1994a:787); é possível para uma geração, no sentido que lhe confere Pierre Nora em "A geração" (1997:2975-3015), um meio de memória cujos aderentes reivindicam uma experiência cuja partilha real ou virtual os torna contemporâneos. Trata-se da constituição correlativa do sujeito, "o modo de objetificação que não é o mesmo segundo o tipo de saber do qual se trata" (Foucault 1994c:632) e do objeto de conhecimento que não permanece o mesmo através dos discursos sucessivos (Foucault 1963:139). "A verdade é desse mundo; ela é aí produzida graças a múltiplos constrangimentos. E ela detém daí efeitos regrados de poder. Cada sociedade tem seu regime de verdade, sua política geral de verdade" (Foucault 1994b:158).

${ }^{32}$ Contanto que elas "esqueçam", sem que aquilo que foi esquecido esteja necessariamente ausente.

${ }^{33}$ Paradoxalmente, é o terceiro lugar de memória, aquele organizado pelo trabalho de memória na empresa (ela tem quase 150 anos), na cidade e na região, um lugar de memória poznaniano, que foi efetivamente reduzido ao silêncio nos anos 1960 e 1970, a ponto de, em 1976, aparecer inaudível, ausente. Rafal Drozdowski e Marek Ziolkowski (2006:39) notam que, em junho de 1976, quando em Poznan o poder impõe uma manifestação pública contra a greve dos operários em Radom e Ursus, nem o partido no poder nem os participantes forçados a dela participar pareciam perceber a coincidência com o 20 aniversário de Junho de 1956.

${ }^{34}$ Invisível e, no entanto, percebido por todos, como a nudez do rei, cujas novas vestes não escondem a nudez. Uma vez sendo conveniente não dizer o que se vê, este patriotismo significa o antissovietismo.

${ }^{35}$ Mesmo que o gesto fosse feito após a comemoração de 2006, a obstinação do presidente Kaczynski em retirar as Brigadas internacionais do panteão nacional polonês, de privar os raros sobreviventes poloneses do estatuto de antigos combatentes nos fala longamente sobre o apego em relação a este símbolo. 
${ }^{36}$ Em 28 de junho de 1986, em um artigo publicado no número especial de Tygodnik Mazowsze (clandestino no estado de guerra), Janusz Palubicki escrevia que a forma de cruz do monumento impedia que o poder o recuperasse visando à propaganda comunista. Contudo, a Internacional havia sido executada pela última vez, que fora provavelmente também a primeira, por ocasião das cerimônias comemorativas de junho de 1989 (Dabertowa \& Lenartowski 1996:43).

37 “Toda política não é senão o produto de uma concatenação de causas; ela não tem totalidade exterior à sua disposição, ela não exprime nada de mais elevado que ela própria, ainda que sua singularidade seja sufocada por nobres generalidades", escreve Paul Veyne (2008:115) a propósito da posição de Foucault que torna impossível o intelectual generalista, "Sartre ou Bourdieu que toma posição em virtude de um ideal da sociedade ou de um sentido da história".

${ }^{38}$ A ilusão é mal dissimulada quando, em 28 de junho de 1981, o cardeal Franciszek Macharski apela em sua homilia para que se vele pela chegada do grande momento histórico (Dabertowa \& Lenartowski 1996).

${ }^{39}$ Esta figura está presente, mas de modo distinto, de uma comemoração à outra. Em 1981, uma rua de Poznan recebeu seu nome. Na placa comemorativa ele é qualificado como "menino herói". Sua mãe é uma convidada de destaque: no sentido literal, ela o representa. No que concerne à sua morte, cujas circunstâncias não são claras, ler Wojciech Augustyniak \& Jan Sandorski (1998:122-124). Em 2006, seu estatuto muda e no espetáculo Czerwiec 56, tu sie zaczelo (Junho de 1956 começou aqui), ele guia a nação em busca de liberdade (ver o CD do espetáculo, Telewizja polska 2006). A importância da criança, inocente mártir, revela o peso do contexto cristão da memória. A propósito de uma outra ocorrência, ver Bogumil Jewsiewicki et al. (1995a:209-237).

${ }^{40}$ O espetáculo, preparado em 1981 por um teatro, o Teatr Nowy, baseava-se nos atos do processo dos acusados de Junho de 1956. Seu título era: "Acusado: junho 56". Uma emissão da televisão polonesa e outras manifestações culturais foram produzidas visando à representação do que ocorrera, tendo como objetivo declarado fazer reviver aqueles que já não eram.

${ }^{41}$ No sentido do efeito real que Roland Barthes identifica na escrita histórica.

${ }^{42}$ Não faço julgamento sobre a adequação entre estes discursos e o objeto total Junho de 1956, fazendo antes um "perspectivismo" à la Foucault do que um relativismo.

${ }^{43}$ Este termo, que pretendíamos ser um conceito científico, tornou-se confusamente polissêmico e somente pode servir ao esclarecimento que fornece ao livro de Ian Hacking (2001).

${ }^{44}$ Em seu poema "On a fusillé mon cœur", Kazimiera Illakowiczowna escreve nos dias que se seguem ao 28 de junho: "O pavimento está salpicado por cérebro e se 
incha lentamente. Ele se põe a pensar, entretanto, mal se ergue e ousa colocar questões 'Por que é sempre o intelectual que governa e sobre os operários que se atira?'”.

${ }^{45}$ Os relatórios dos serviços de segurança indicavam que os tamancos (fornecidos como vestimenta de trabalho) representavam um risco de ferimento para muitos operários, já que o solado de madeira era bastante escorregadio. Sua substituição por botas mais seguras fazia parte das reivindicações operárias que o poder não levou em conta.

${ }^{46}$ A literatura sobre o testemunho cresce rapidamente. Destacamos Esthétique du témoignage (Dornier \& Dulong 2005).

47 "As consequências da revolução de julho serão memoráveis. Esta revolução proclamou a pena de morte contra todos os tronos; os reis somente poderão reinar atualmente por meio da violência das armas; meio assegurado por um momento, mas que não poderia durar [...]" (Chateaubriand 1973:251). Em 1981, inscrever sobre a primeira cruz 1956 e sobre a segunda 1968, 1970, 1976, 1980, o todo localizado sob o olhar da águia polonesa, já falava sobre o caráter fundador de Junho de 1956. No entanto, a maneira como a águia estava colocada parecia situar esta leitura possível sob sua autoridade. Acrescentar, em 1991, a data de 1981 (explicada então como data de proclamação do estado de guerra) muda evidentemente o curso da história. A cerimônia comemorativa de junho de 1981, declarada pelo cardeal Macharski "véspera do momento histórico", encerra um tempo para preparar outro, o da comemoração de 2006. O cardeal inspirava-se provavelmente de maneira explícita no poema de 1974 "Myslac ojczyzna" (Pensando a pátria), de Karol Wojtyla (já papa em 1981). Wojtyla dirigia-se ao povo que não deveria "esquecer ter sido enviado para velar a chegada de sua hora".

${ }^{48}$ Muitas fotografias desse episódio estão disponíveis, ver Poznan in June 1956. A Rebelious City, catálogo da exposição em Poznan, 2006. Elas mostram uma mulher jovem entre os manifestantes. Ela é identificada como uma condutora de bonde; ao menos duas identificações diferentes são propostas. A fotografia, publicada em 7 de julho de 1956 na capa do The Illustrated London, é feita de um ângulo que faz da mulher aquela que conduz a marcha e da bandeira, seu véu protetor, enquanto a mancha de sangue poderia ser identificada com a águia. Solidarnosc, clandestina após a proclamação do estado de guerra, havia produzido duas imitações de selos, uma reproduzindo esta fotografia e outra com o retrato de Romek Strzalkowski (Dabertowa \& Lenartowski 1996, fig. 91; e "Kronika polskiego powstania. Czerwiec 1956", zeszyt 5, Gazeta Wyborcza, Poznan, juin 2006).

${ }^{49}$ Analisei o papel análogo que teve a imagem da Virgem negra de Czestochowa carregada por Lech Walesa sobre um estandarte (Jewsiewicki 1995b).

${ }^{50}$ Veyne (2008:99) escreveu: "A Europa tem todo um amplo patrimônio cristão, ela mora em uma velha casa na qual se veem nos muros quadros religiosos".

${ }^{51}$ Os arquivos da milícia, do exército e sobretudo dos serviços de segurança são acessíveis; vários documentos secretos, numerosas fotos tiradas por agentes secretos 
foram tornados públicos em Rozstrzelana nadzieja. Poznanski czerwiec 1956, Poznan, Glos Wielkopolski (2006) e Poznan in June 1956 [...]. A historiografia é bastante abundante; já em 1991, em Poznan, Maciej Roman Bombicki publica uma rica coletânea de documentos, Poznan '56, nas edições Lawica.

52 À maneira de Francis Fukuyama (1993).

${ }^{53}$ Não seria a razão profunda da ausência de uma figura de herói-símbolo de junho de 1956, personagem vivo que o teria dotado de um rosto, investindo-o de uma autoridade simbólica? Rafal Drozdowski e Marek Ziolkowski (2006:36) observam justamente que todos os grandes acontecimentos posteriores produziram tal autoridade. Junho de 1956 tem uma única vítima-símbolo: Romek Strzalkowski.

${ }^{54}$ Em 1991, por ocasião da celebração do 35 Aniversário de Junho de 1956, como ponto de partida do processo de liberação do comunismo da Europa central e oriental. Devemos isto a uma figura histórica da resistência contra a ocupação nazista, Jan Nowak Jezioranski (Eugenia Renia Dabertowa \& Marek Lenartowski 1996:87). Uma exposição fotográfica "Poznan-Budapest" foi então organizada.

${ }^{55}$ No contexto das cerimônias de construção do monumento, em 27 de junho de 1981, o vice-primeiro ministro polonês de então, Jerzy Ozdowski, parece ter sido o primeiro a articular esta ideia, chamando Junho de 1956 de pai de agosto de 1980 (Dabertowa \& Lenartowski 1996:43).

${ }^{56}$ No espetáculo Junho de 1956, é o menino que personifica Romek Strzalkowski que assume o lugar ocupado pela mulher da célebre foto. Ele se prostra diante da multidão, a bandeira polonesa na mão (Gazeta Wyborcza, 29 de junho de 2006, p. 3).

${ }^{57}$ Como enfatiza Pawel Machcewicz (2006:27), diretor do Bureau da Educação Pública do Instituto da Memória Nacional de 2000 a 2005, Solidanorsc tinha escolhido em 1981 comemorar junho ao invés de outubro de 1956, já que os acontecimentos de Poznan atualizam a revolta operária, ao passo que outubro reencaminha para as lutas internas no seio do Partido Comunista.

${ }^{58}$ Foi ainda Machcewicz (2006:27) que disse, por ocasião do colóquio comemorativo de 8 de maio de 2006, na Universidade de Poznan, que Junho de 1956 inaugurava o ciclo que conduziu à queda do sistema comunista, sendo assim a última insurreição polonesa. Junho de 1956 seria, portanto, esta articulação entre a conclusão do ciclo sacrificial de um século e meio de cativeiro - ao longo do qual o povo não parou de se manifestar a fim de que o espírito nacional não morresse - e a saída polonesa do Egito. A cobertura da placa na qual figura seu texto representa o monumento sobre o fundo de uma foto de arquivo da multidão, em 28 de junho de 1956, na praça em que hoje figura o monumento.

${ }^{59}$ Seria preciso outro artigo para analisar a transposição deste contexto à "santificação" deste presidente tragicamente morto por ocasião de um acidente de 
avião, o qual transportava a delegação polonesa que iria participar da comemoração russo-polonesa do $70^{\circ}$ Aniversário do massacre dos oficiais poloneses em Katyan. Notemos somente que neste caso também cruzes, milhares de cruzes em 2010 e não apenas três, serviram para a santificação de um espaço que passou a ser interditado ao adversário assim estigmatizado, para não dizer diabolizado.

${ }^{60}$ Em 1945, Hannah Arendt escreveu em Partisan Review que o problema do Mal será a questão fundamental da vida intelectual do pós-guerra na Europa (artigo retomado em Essays in understanding 1994:133-135). O problema do mal encarnado pelo nazismo responsável pelo extermínio de judeus da Europa assombra a consciência ocidental. A partir dos anos 1960, este Mal incorpora não somente a colaboração, mas também a responsabilidade moral daqueles que sabiam mas nada tinham feito ou que fizeram muito pouco tarde demais. Os Estados Unidos encontram-se implicados (Novick 2001) e o problema do Mal toca a consciência ocidental. Apesar de todas as críticas das quais foi objeto, Ernst Nolle, ao sustentar que o comunismo foi não somente o antecedente histórico do nazismo mas também a sua causa, permite incluir o comunismo nesse Mal. Em seguida, os descendentes das vítimas do tráfico negreiro, da colonização demandam reconhecimento deste fato como crimes de responsabilidade do Ocidente - as faces do Mal multiplicam-se. Ver o excelente artigo de Tony Judt (2008:33-35) baseado em sua conferência proferida por ocasião do recebimento do Prêmio Hannah Arendt.

${ }^{61}$ A propósito do comentário de Soeren Kierkegaard (1967:116) sobre a expressão "Bem-aventurados aqueles que não viram e que acreditaram" (João 20, 29).

${ }^{62}$ Chateaubriand, Mémoires d'outre-tombe, livro XVI, capítulo 10, citado por Terray (2000).

\section{Referências bibliográficas}

ARENDT, Hannah. 1994. Essays in understanding. New York: Harcourt Brace.

ASSMANN, Jan. 2006. Religion and cultural memory. Stanford: Stanford University Press.

AUGUSTYNIAK, Wojciech \& SANDORSKI, Jan. 1998. "Prawne aspekty odpowiedzialnosci za poznanski czerwiec 1956". In: Przelomowy rok 1956. Poznan: Wydawnictwo poznanskie.
BAZIN, Jean. 2000. "Sciences des mœurs et description de l'action". Le Genre Humain, 35:33-58.

BOLTANSKI, Luc. 2000. "Une sociologie sans société ?". Le Genre Humain, 35:303-311.

. \& THÉVENOT, Laurent. 1991. De la justification. Les économies de la grandeur. Paris: Gallimard.

BOURDIEU, Pierre. 1980. Le sens pratique. Paris: Éditions de Minuit. 
. 1982. Ce que parler veut dire: l'économie des échanges linguistiques. Paris: Fayard.

CASTEL, Robert. 2000. "Configurations historiques et problématisation du présent". Le Genre Humain, 35:162-179.

CHATEAUBRIAND, François-René de. 1973. Mémoires d'outre-tombe. Paris: Librairie Générale d'Édition.

DABERTOWA, Eugenia Renia \& LENARTOWSKI, Marek. 1996. Pomnik poznanskiego czerwca 1956. Poznan: Komisja Zakladowa NSZZ "Solidarnosc" H. Ciegelski - Poznan S.A.

DE CERTEAU, Michel. 1980. L'invention du quotidien, tome I: Arts de faire. Paris: UGE.

DESCOMBES, Vincent. 2000. "Qu'est-ce que être contemporain?". Le Genre Humain, 35:15-32.

DORNIER, Carole \& DULONG, Renaud (dir.). 2005. Esthétique du témoignage. Paris: Éditions de la Maison des Sciences de l'Homme.

DROZDOWSKI, Rafal \& ZIOLKOWSKI, Marek. 2006. "Poznanski Czerwiec w pamieci Polakow. In: Poznanski czerwiec '56. Sens pamieci. Poznan: Wydawnictwo Naukowe UAM.

DUCROT, Oswald. 2000. "Pourquoi la synchronie?". Le Genre Humain, 35: 133:161.

FOUCAULT, Michel. 1963. Naissance de la clinique: une archéologie du regard médical. Paris: Presses Universitaire de France.

. 1969. L'archéologie du savoir. Paris: Gallimard. . 1994a. Dits et écrits, v. I. Paris: Gallimard. . 1994b. Dits et écrits, v. III. Paris: Gallimard,. 1994c. Dits et écrits, v. IV. Paris: Gallimard.

FUKUYAMA, Francis. 1993. La fin de l'histoire et le dernier homme. Paris: Flammarion.
GOODWYN, Lawrence. 1991. Breaking the barrier: the rise of solidarity in Poland. Oxford: Oxford University Press.

HACKING, Ian. 2001. Entre science et réalité. La construction sociale de quoi? Paris: La Découverte.

HALBWACHS, Maurice. 1994. Cadres sociaux de la mémoire. Paris: Albin Michel.

HARTOG, François. 2003. Régimes d'historicité. Présentisme et expériences du temps. Paris: Seuil.

JAUSS, Hans Robert. 1982. Toward an aesthetic of reception. Minneapolis: University of Minnesota Press.

JEWSIEWICKI, Bogumil; MBUYAMBA, Flory-Kante \& NGOMBU, Danielle Mwadi wa. 1995a. "Du témoignage à l'histoire, des victimes aux martyrs: la naissance de la démocratie à Kinshasa". Cahiers d'Études Africaines, 137:76-98.

JEWSIEWICKI, Bogumil. 1995b. "The identity of memory and the memory of identity". Social Identities, 2:227-261.

JUDT, Tony. 2008. "The 'problem of evil' in postwar Europe". New York Review of Books, 14:33-35.

KIERKEGAARD, Soeren. 1967. Les miettes philosophiques. Paris: Seuil.

LADORSKI, Henryk. 1992. Niepokonani '56 Poznań. Poznań: Pallotinum.

LATOUR, Bruno. 2006. Changer de sociétéRefaire de la sociologie. Paris: La Découverte.

LAVABRE, Marie-Claire. 2006. "Sociologie de la mémoire/histoire de la mémoire". In: Bogumil Jewsiewicki (dir.), Travail de mémoire et d'oubli dans les sociétés postcommunistes. Bucarest: Éditions de l'Université de Bucarest.

LEPETIT, Bernard. 2000. "La mémoire des formes". Le Genre Humain, 35:59-75.

LYOTARD, Jean-François. 1984. Le différent. Paris: Éditions de Minuit. .1991. "Survivant". In: Lectures d'enfance. Paris: Galilée. 
MACHCEWICZ, Pawel. 2006. "Miejsce Poznanskiego Czerwca w histori Polski i Europy Srodkowo-Wschodniej". In : Poznanski czerwiec '56. Sens pamieci. Poznan: Wydawnictwo Naukowe UAM.

NIETZSCHE, Frédéric. 1990. "Considérations inactuelles, II. De l'utilité et des inconvénients de l'histoire pour la vie". In: Oeuvres philosophiques complètes, t. II, v. 1. Paris: Gallimard.

NORA, Pierre. 1997 [primeira edição de 1984 à 1992]. Lieux de mémoire, "quarto", v. 2. Paris: Gallimard.

NOVICK, Peter. 2001. L'Holocauste dans la vie américaine. Paris: Gallimard.

PROCHASSON, Christophe. 2008. L'empire des émotions. Les historiens dans la mêlée. Paris: Demopolis.

REVEL, Jean. 2000. "Pratiques du contemporain et régimes d'historicité". Le Genre Humain, 35:14-15.

RICOEUR, Paul. 2000. Mémoire, histoire, oubli. Paris: Seuil.

SCHAEFFER, Jean-Marie. 2007. La fin de l'exception humaine. Paris: Gallimard.

SOJKA, Jacek. 2006. "Sens pamieci". In: Poznanski czerwiec '56. Sens pamieci. Poznan: Wydawnictwo Naukowe UAM.

TAYLOR, Charles. 2004. Modern social imaginaries. Durham: Duke University Press.

TERRAY, Emmanuel. 2000. "L'histoire et les possibles". Le Genre Humain, 35:179-191.

VEYNE, Paul. 2008. Foucault. Sa pensée, sa personne. Paris: Albin Michel.

WILliAMS, Bernard. 2006. Vérité et véracité. Essai de généalogie. Paris: Gallimard. 
Resumo

A partir da breve reconstituição de um evento tomado em sua dinâmica interna, o autor examina as fases sucessivas em sua apropriação memorial, seguindo os objetivos dos atores, o contexto da atribuição de sentido e os meios utilizados por diversos atores. Ele procura mostrar de que modo opera a apropriação do evento pelos atores por meio de ações sucessivas de patrimonialização de sua memória sensível, quer seja sob a forma de um monumento ou de um espetáculo comemorativo. A memória viva é substituída pela comemoração institucionalizada, e os atores do evento apagam-se diante de figuras heróicas construídas segundo as necessidades do contexto de atribuição de sentido correspondente aos objetivos dos atores institucionais.

Palavras-chave Trabalho de memória, Comemoração, Experiência, Patrimônio, Antropologia do sensível.

\section{Abstract}

Setting out from the brief reconstruction of an event and its internal dynamic, the author examines the successive phases involved in its mnemonic appropriation, tracing the objectives and practices of the various actors involved and the shifting contextual meanings. It shows how the event is appropriated by the actors through the successive transformation of its living memory into heritage, either in the form of monuments or commemorations. Living memory is replaced by institutionalized remembrance and the event's actors by heroic figures constructed according to the contextual meanings elicited by the demands and objectives of the institutional actors.

Key words Work of Memory, Commemoration, Experience, Heritage, Anthropology of the Sensible. 